\title{
Screening of young children between 2-24 months of Age with a first febrile UTI for VUR with imaging modalities
}

\author{
Alkarani T Patil ${ }^{1}$, Sanjeeva G N ${ }^{2}$, Yogesh $R^{3}$, Sowmya $K^{4}$, Ramesh $L^{5}$ \\ ${ }^{1}$ Dr Alkarani T Patil, Associate professor, Department of Pediatrics, ${ }^{2}$ Dr Sanjeeva G N*, Assistant professor, Department \\ of Pediatrics, ${ }^{3}$ Dr.Yogesh R, Post Graduate, Department of Pediatrics, ${ }^{4}$ Dr. Sowmya K, Post Graduate, Department of \\ Pediatrics, ${ }^{5}$ Dr. Ramesh L, Professor of Radiology, Indira Gandhi Institute of Child Health, Bangalore, Karnataka, India.
}

Address for Correspondence: Dr Sanjeeva G N, 201, "Eshavasyam”, $4^{\text {th }}$ main, Samvruddhi enclave, Subramanya Pura post, Bangalore, Email: sanju_gn@ rediffmail.com, sanju.gn26@gmail.com

\begin{abstract}
Background: Urinary tract infection (UTI) is one of the most common serious bacterial illnesses affecting children. The presence of moderate to severe vesicouretheral reflux (VUR), particularly if bilateral, is an important risk factor for pyelonephritis and renal scarring. Imaging studies, including renal ultrasonography (USG), technetium-99m- labelled dimercaptosuccinic acid (DMSA) scanning, and voiding cystourethrography (VCUG), are part of standard care after diagnosis of a first UTI in young children. This study was done to determine the sensitivity, specificity and predictive values of renal USG and DMSA scan findings for VUR. Methods: All children between 2-24 months of age presenting with first febrile UTI were prospectively studied. All infants were hospitalized and investigated using renal USG, DMSA scan, and VCUG after diagnosis. The association among findings of USG, DMSA scan, and VCUG were evaluated. Results: A total of 48 children were included in the study and screened, out of which there were abnormal results in 22 (45.8\%) USG and 29(60.4\%) DMSA scan. All grade VUR (I-V) was present in 8(16.7\%) patients and high grade VUR (III-V) was present in 7(14.6\%) patients. The sensitivities for detecting VUR of renal USG alone (75\%) or DMSA scan alone $(87.5 \%)$ were not as good as that of the "OR rule" strategy, which had $100 \%$ sensitivity and $100 \%$ negative predictive value. Conclusions: Renal USG and DMSA scanning both should be routinely performed in young children with a first febrile UTI. VCUG is only indicated when abnormalities are apparent on either USG scanning or DMSA scanning or both.
\end{abstract}

Keywords: Urinary Tract Infection, Vesicoureteral Reflux, Renal Ultrasonography, Dimercaptosuccinic Acid Scan, Voiding Cystourethrography.

\section{Introduction}

UTI is one of the most common serious bacterial illnesses affecting children, particularly infants and young children [1]. It is the third most common infection in paediatric age group, rank next to respiratory and gastrointestinal infections and account for 4 to $10 \%$ of febrile children admitted to hospital [2]. UTI is defined by combination of positive urine culture (any growth of bacteria in urine from a suprapubic bladder aspiration or $>5 \times 10^{4}$ colony-forming units per millilitre in a catheterized specimen or $>10^{5}$ colonyforming units per millilitre from midstream clean catch) and fever $\geq 38.0^{\circ} \mathrm{C}\left(100.4^{\circ} \mathrm{F}\right)[3,4]$. UTI should be

Manuscript received: $3^{\text {rd }}$ Nov 2015

Reviewed: $10^{\text {th }}$ Nov 2015

Author Corrected: $29^{\text {th }}$ Nov 2015

Accepted for Publication: $3^{\text {rd }}$ Dec 2015 suspected in an infant or child presenting with unexplained fever beyond 3 days [5]. All febrile UTI are considered to involve the upper urinary tract with potential for renal scarring [6]. Rapid evaluation and treatment of UTI is important to prevent renal parenchymal damage (renal scarring) that can cause hypertension and chronic renal failure later.

UTI is often associated with VUR or urinary tract obstruction, associated with frequent recurrence of UTI and permanent renal damage [7]. VUR is seen in 40$50 \%$ infants and $30-50 \%$ children with UTI, and resolves with age. Its severity is graded using the International Study Classification from grade I to V, based on the appearance of the urinary tract on VCUG [3]. 
The presence of moderate to severe VUR, particularly if bilateral, is an important risk factor for pyelonephritis and renal scarring [8].

\section{Material and Methods}

This prospective observational study was conducted during Jan 2013 to Dec 2013 at Indira Gandhi Institute of Child Health, Bangalore. All children between 2 months to 24 months of age who present with first febrile UTI confirmed with a positive result on a urine culture were included in the study. Children with proven congenital malformations of the genito-urinary system or neurologic disease, with previous history of UTI, and history of prior antibiotic administration for the present complaints were excluded for the study. The eligible children were enrolled into the study after obtaining informed consent from the parents. A detailed history of the present complaints was taken in a prestructured proforma. A detailed clinical examination was done to rule out any congenital malformations of genito-urinary system or neurologic disease. Blood sample was drawn from all children for complete hemogram and blood CRP (quantitative) estimation and urine sample was collected by suprapubic aspiration for urine microscopy and culture before administration of parental antibiotics. Children with positive urine culture were enrolled in the study and antibiotics changed according to sensitivity pattern and continued for 10-14 days.

Bladder and renal USG was performed within 3 days of admission by an experienced pediatric radiologist. All abnormal USG findings were recorded, including dilatation of the pelvis, calyx, ureter or posterior urethra, thickened pelvic wall (circumferential hypoechoic rim delineated on each side by thin hyperechoic lines, the rim being thicker than $0.8 \mathrm{~mm}$ ) [9] , or bladder (>3 mm in a full or $5 \mathrm{~mm}$ in an empty bladder) [10] , swelling or thinning of renal parenchyma, diffuse or focal increased renal echogenicity with absence of corticomedullary differentiation, renal abscess, and signs of renal hypodysplasia (i.e., small kidney, thinned or hyperechoic cortex, and cortical cysts), or a duplicated collecting system. Renal length was regularly measured from the back, and the reference value was based on normograms described by Miranda et al. [11]. Renal length $>2$ standard deviation scores (SDS) or $<-2$ SDS was considered abnormal.

Technetium-99-m-DMSA scan was performed within 5 days after admission and was considered normal when homogenous uptake of the isotope was evident throughout the kidneys and the renal contour was preserved. APN was diagnosed if there was a focal or multiple areas of diminished isotope uptake with preserved renal contour or when the kidney was enlarged with diffuse decrease in uptake. Renal cortical scars were reported when there were defects in uptake associated with cortical loss and decreased renal volume. A small kidney with diffusely decreased isotope uptake and decreased differential renal function was reported as renal hypodysplasia.

A VCUG was performed 10-14 days after appropriate antibiotic treatment. Series of images was obtained to determine whether any liquid travelled backwards into 1 or both ureters when the patient emptied his or her bladder. VUR was graded according to recommendations of the International Reflux Study in Children [12]. Children with grades I-II reflux are defined as low grade VUR and grades III- V reflux as high-grade VUR. In Children with bilateral VUR, the higher grade of the two ureters was recorded.

\section{Study definitions}

- UTI is defined by combination of fever $\geq 38.0^{\circ} \mathrm{C}$ $\left(100.4^{\circ} \mathrm{F}\right)$ and positive urine culture $[3,4]$.

- VUR is the retrograde flow of urine from the bladder into the ureter and toward the kidney secondary to a dysfunctional vesicoureteric junction [13].

To assess the usefulness of imaging studies in screening for VUR, which indicated the need for VCUG, four approaches were compared:

- USG alone.

- DMSA scan alone,

- "OR rule" - defined as the routine performance of both USG and DMSA scan in all children with first febrile UTI. An abnormality on either study or on both constituted an indication for VCUG.

- "AND rule" - defined as performance of VCUG only if both USG and DMSA scan were abnormal. [14].

The diagnostic significance of renal US, DMSA scan, OR rule, and AND rule strategies in relation to the presence of all (I-V) or high-grade VUR was assessed by odds ratios (ORs) using logistic regression analysis. Sensitivity, specificity, positive predictive value (PPV) and negative predictive value (NPV), positive and negative likelihood ratios (LR) for all and high-grade VUR of these methods were calculated. (Fig 1) 
Fig1: Study protocol

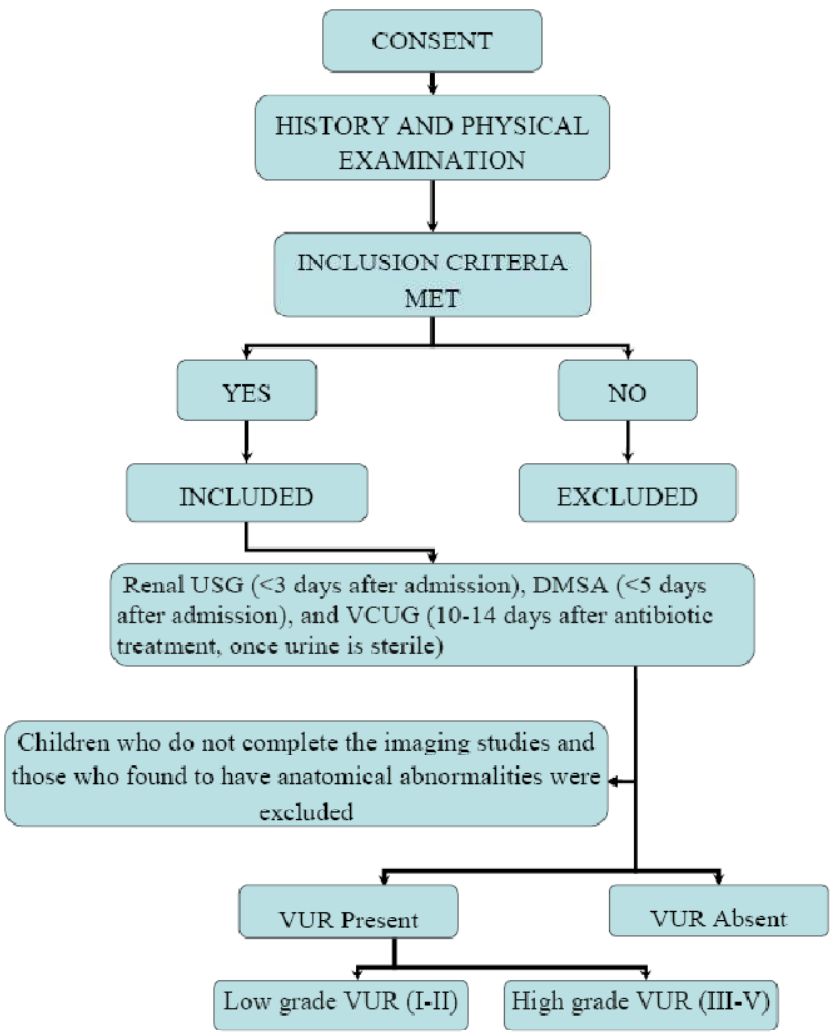

\section{Results}

A total of 48 eligible patients were admitted and investigated for the study purpose in Indira Gandhi Institute of Child Health, Bangalore. Approval from the institutional ethical committee of IGICH was taken. Baseline parameters of the study subjects were depicted in table 1. The most common causative agent was Escherichia coli, affecting 36 (75\%) patients (table1).

Table 1: Baseline parameters

\begin{tabular}{|l|c|c|c|}
\hline Characteristics & Male & Female \\
\hline \multicolumn{3}{|c|}{ Age and Gender distribution } \\
\hline $2-12$ months & $14(45.2 \%)$ & $7(41.2 \%)$ & $21(43.7 \%)$ \\
\hline $12-24$ months & $17(54.8 \%)$ & $10(58.8 \%)$ & $27(56.3 \%)$ \\
\hline Total & $31(100 \%)$ & $17(100 \%)$ & $48(100 \%)$ \\
\hline \multicolumn{3}{|c|}{ Microbiology of Urine culture } \\
\hline Escherichia coli & $22(46 \%)$ & $14(29 \%)$ & $36(75 \%)$ \\
\hline Klebsiella oxytoca & $4(8.5 \%)$ & $2(4 \%)$ & $3(12.5 \%)$ \\
\hline Enterobacter Sps & $2(4.2 \%)$ & $1(2.1 \%)$ & $2(4.2 \%)$ \\
\hline Citrobacter diversus & $2(4.2 \%)$ & 0 & $1(2.1 \%)$ \\
\hline Proteus merabilus & $1(2.1 \%)$ & 0 & \\
\hline
\end{tabular}

VUR of any grade was diagnosed in 8 patients (16.7\%; 4 boys, 4 girls), and high-grade VUR was present in 7 patients (14.6\%; 4 boys, 3 girls). (Table 2) 
Table 2: VCUG findings according to VUR Grading

\begin{tabular}{|c|c|c|c|c|}
\hline \multirow{2}{*}{\multicolumn{2}{|c|}{ Finding }} & \multicolumn{3}{|c|}{ Number of children } \\
\hline & & Boys & Girls & Total \\
\hline \multicolumn{2}{|c|}{ No VUR } & $27(56.2)$ & $13(27.1)$ & $40(83.3 \%)$ \\
\hline \multicolumn{2}{|l|}{ VUR } & $4(8.35 \%)$ & $4(8.35 \%)$ & $8(16.7 \%)$ \\
\hline & Grade I & 0 & 0 & 0 \\
\hline & Grade II & 0 & 1 & $1(2.1 \%)$ \\
\hline & Grade III & 1 & 1 & $2(4.2 \%)$ \\
\hline & Grade IV & 1 & 0 & $1(2.1 \%)$ \\
\hline & Grade V & 2 & 2 & $4(8.3 \%)$ \\
\hline
\end{tabular}

Of 48 children, $22(45.8 \%)$ US results and 29 (60.4\%) DMSA scan results were abnormal (Table 3). A total of 35 children $(72.9 \%)$ had abnormalities on ultrasound scanning, DMSA scanning, or both.

Table 3: Usefulness of renal ultrasound, DMSA scan, "OR rule", and "AND rule" strategies for detecting all grade VUR and high-grade VUR

\begin{tabular}{|c|c|c|c|c|c|c|}
\hline \multirow[t]{2}{*}{ Test } & \multicolumn{2}{|c|}{ All-grade VUR } & \multirow{2}{*}{$\begin{array}{c}\text { Odds } \\
\text { Ratio } \\
(95 \% \mathrm{CI})\end{array}$} & \multicolumn{2}{|c|}{$\begin{array}{c}\text { High-grade } \\
\text { VUR }\end{array}$} & \multirow{2}{*}{$\begin{array}{c}\text { Odds } \\
\text { Ratio } \\
(95 \% \mathrm{CI})\end{array}$} \\
\hline & $\begin{array}{c}\text { Absent } \\
(n=40)\end{array}$ & $\begin{array}{c}\text { Present } \\
(n=8)\end{array}$ & & $\begin{array}{c}\text { Absent } \\
(n=41)\end{array}$ & $\begin{array}{c}\text { Present } \\
(n=7)\end{array}$ & \\
\hline \multicolumn{7}{|l|}{ Renal ultrasound } \\
\hline - $\quad \square$ Abnormal & 16 & 6 & \multirow{2}{*}{$\begin{array}{c}4.5 \\
(0.8-25.1)\end{array}$} & 17 & 5 & \multirow{2}{*}{$\begin{array}{c}3.52 \\
(0.6-20.4)\end{array}$} \\
\hline - $\square$ Normal & 24 & 2 & & 24 & 2 & \\
\hline \multicolumn{7}{|l|}{ DMSA scan } \\
\hline - $\square$ Abnormal & 22 & 7 & \multirow{2}{*}{$\begin{array}{c}5.73 \\
(0.64-50.9)\end{array}$} & 22 & 7 & \multirow{2}{*}{$\begin{array}{c}13.0 \\
(0.7-242)\end{array}$} \\
\hline • $\square$ Normal & 18 & 1 & & 19 & 0 & \\
\hline \multicolumn{7}{|l|}{ OR rule } \\
\hline • $\square$ Abnormal & 27 & 8 & \multirow{2}{*}{$\begin{array}{c}8.34 \\
(0.45- \\
155)\end{array}$} & 28 & 7 & \multirow{2}{*}{$\begin{array}{c}7.1 \\
(0.37-133)\end{array}$} \\
\hline - $\square$ Normal & 13 & 0 & & 13 & 0 & \\
\hline \multicolumn{7}{|l|}{ AND rule } \\
\hline - $\quad \square$ Abnormal & 11 & 5 & \multirow{2}{*}{$\begin{array}{c}4.39 \\
(0.9-21.6)\end{array}$} & 11 & 5 & \multirow{2}{*}{$\begin{array}{c}6.8 \\
(1.15-40.4)\end{array}$} \\
\hline - $\square$ Normal & 29 & 3 & & 30 & 2 & \\
\hline
\end{tabular}

Ultrasound scanning results were abnormal in $22(45.8 \%)$ children, out of which $6(12.5 \%)$ children had VUR, 5 had high-grade VUR ( grade IV, 1; grade V, 4) and 1 had low grade VUR(Grade II). However, 2 patients with grade III VUR had normal findings and would have been missed if this was the only screening test. Therefore, the sensitivity and negative predictive value of ultrasound scanning for VUR was $75 \%$ and $92.3 \%$ respectively.

Of the 29 children with abnormal DMSA scan results, 7 had VUR and all 7 were high-grade VUR. However, 1 patient with low grade VUR had normal DMSA scan results, making the sensitivity and negative predictive value of DMSA scanning $87.5 \%$ and $94.7 \%$, respectively, and would have been missed if this was the only screening test.

On the basis of the AND rule strategy, 17 children would have undergone VCUG, of whom 5 had high-grade VUR (grade IV, 1; grade V, 4). Of the 31 patients with no abnormalities on either test, 2 had grade III VUR and 1 had grade II VUR. The AND strategy thus had a sensitivity of $62.5 \%$ and a negative predictive value of $90.6 \%$.

On the basis of the OR rule strategy, 35 children would have undergone VCUG, of whom 7 had high-grade VUR (grade III, 2; grade IV, 1; grade V, 4) and 1 had low grade VUR(grade II). None of the VUR cases were missed if this strategy 
was taken as a screening test. The OR rule strategy thus had a sensitivity of $100 \%$ and a negative predictive value of 100\%. (Table 3)

The calculated sensitivity, specificity, PPV, NPV, and positive or negative LRs for all and high-grade VUR of the four methods is depicted in Table 4.

Table 4: Diagnostic characteristics of renal ultrasound, DMSA, “OR rule", and "AND rule" strategies for detecting all grade VUR and high-grade VUR in children aged 2 months to 24 months with febrile UTI.

\begin{tabular}{|l|c|c|c|c|c|c|c|c|}
\hline \multirow{2}{*}{ Parameter } & \multicolumn{5}{|c|}{ All-grade VUR } & \multicolumn{3}{|c|}{ High-grade VUR } \\
\cline { 2 - 9 } & $\begin{array}{c}\text { Renal } \\
\text { Ultrasound }\end{array}$ & $\begin{array}{c}\text { DMSA } \\
\text { Scan }\end{array}$ & $\begin{array}{c}\text { OR } \\
\text { rule }\end{array}$ & $\begin{array}{c}\text { AND } \\
\text { rule }\end{array}$ & $\begin{array}{c}\text { Renal } \\
\text { ultrasound }\end{array}$ & $\begin{array}{c}\text { DMSA } \\
\text { scan }\end{array}$ & $\begin{array}{c}\text { OR } \\
\text { rule }\end{array}$ & $\begin{array}{c}\text { AND } \\
\text { Rule }\end{array}$ \\
\hline $\begin{array}{l}\text { Sensitivity, } \\
\text { Specificity, }\end{array}$ & $75 \%$ & $87.5 \%$ & $100 \%$ & $62.5 \%$ & $71.43 \%$ & $100 \%$ & $100 \%$ & $71.4 \%$ \\
\hline $\begin{array}{l}\text { PPV, \% } \\
\text { NPV, \% }\end{array}$ & $27.3 \%$ & $24.1 \%$ & $22.8 \%$ & $31.25 \%$ & $22.7 \%$ & $24.1 \%$ & $20 \%$ & $31.2 \%$ \\
\hline $\begin{array}{l}\text { Positive } \\
\text { Likelihood } \\
\text { Ratio }\end{array}$ & $92.3 \%$ & $94.7 \%$ & $100 \%$ & $90.6 \%$ & $92.3 \%$ & $100 \%$ & $100 \%$ & $93.7 \%$ \\
\hline $\begin{array}{l}\text { Negative } \\
\text { Likelihood } \\
\text { Ratio }\end{array}$ & 1.87 & 1.59 & 1.48 & 2.24 & 1.72 & 1.86 & 1.46 & 2.66 \\
\hline Accuracy & $62.5 \%$ & $52.08 \%$ & $43.75 \%$ & $70.83 \%$ & $60.4 \%$ & $54.2 \%$ & $41.67 \%$ & $72.92 \%$ \\
\hline
\end{tabular}

\section{Discussion}

Several reports suggest that acute DMSA scan with or without renal US may be used as screening test to identify high-grade VUR. The risk of APN and subsequent scarring, is substantially higher in patients with high-grade VUR [15,16]. Our approach aims at predicting children at high risk for VUR and evaluating them more thoroughly, while avoiding VCUGs in children who do not need them.

Ultrasound scanning is a good tool to assess obstructive uropathies, urolithiasis, ectopic kidney or ureter, and duplication of the collecting system with or without ureterocele. It is less reliable, however, for demonstrating APN, renal scarring and detecting VUR, perhaps because reflux is an intermittent, dynamic event $[4,17,18]$.

The sensitivity of ultrasound scanning in our study was $75 \%$, which is comparable with that of other studies. Three signs, including renal hypodysplasia, hydronephrosis, and hydroureter, were the most reliable clues for predicting high grade VUR.

In our study the sensitivity, specificity, positive predictive value and negative predictive value of ultrasound scanning for high grade VUR was $71.4 \%$, $58.5 \%, 22.7 \%$ and $92.3 \%$ respectively. DMSA renal scanning is the most sensitive tool for detecting APN and renal scarring, with sensitivity for APN of approximately 90\% [19]. DMSA scanning now increasingly plays a prominent role in evaluating the condition of children with a febrile UTI $[1,15]$. As with ultrasound scanning, however, normal scan results cannot absolutely exclude high-grade VUR.

In our study the sensitivity, specificity, positive predictive value and negative predictive value of DMSA scanning for high grade VUR was $100 \%$, $46.3 \%, 24.1 \%$ and $100 \%$ respectively. DMSA scanning results in our study in detecting high grade VUR is comparable with other studies.

In Fouzas et al [20], performance of DMSA scanning was 7-14 days after diagnosis of UTI compared to other studies were its performed earlier ( $<5$ days of admission in Tsai et al [21], within 2 days after diagnosis in Tseng et al [1] and median of 5 days after admission in Preda et al [22]). This could explain our higher sensitivity of DMSA scan for detecting high grade VUR than Fouzas et al [20]. 
In our study, on the basis of the OR rule strategy, 35 children would have undergone VCUG, of whom 7 had high-grade VUR (grade III, 2; grade IV, 1; grade V, 4) and 1 had low grade VUR(grade II). None of the VUR cases were missed if this strategy was taken as a screening test. The OR rule strategy thus had a highest sensitivity of $100 \%$ and a negative predictive value of $100 \%$ in screening high grade VUR. This is comparable with other similar studies, Lee et al [23] and Tsai et al [21].

In the present study, on the basis of the AND rule strategy, 17 children would have undergone VCUG, of whom 5 had high-grade VUR (grade IV, 1; grade V, 4). Of the 31 patients with no abnormalities on either test, 2 had grade III VUR and 1 had grade II VUR. The AND rule strategy has a better specificity $(73.2 \%)$ compared to OR rule strategy, renal USG alone or DMSA scan alone, with the cost of decreased sensitivity (62.5\%). If this strategy is taken as screening test then would have missed 3 patients with VUR.

With a high sensitivity and NPV, the OR rule strategy may be used as a good screening tool for detecting high-grade VUR. If VCUG is performed only in children with abnormal results on renal USG, DMSA, or both, $13(27.1 \%)$ fewer VCUGs will be performed. In this study, we only assess the value of acute DMSA and renal USG in revealing high-grade VUR but do not provide information about long-term renal consequences. Because the benefit of identifying highgrade VUR is still in doubt, this screening strategy is useful only when intervention of high-grade VUR can be proved to change a patient's future risk or long-term outcome.

\section{Conclusion}

In conclusion, renal USG and DMSA scan have different but complementary roles in evaluating kidneys and urinary tract. The OR rule strategy has the highest sensitivity and NPV for screening high-grade VUR. Hence would recommend to use OR rule strategy as a screening tool for detecting high grade VUR and to perform VCUG in patients with abnormal result in OR rule strategy.

Acknowledgements: We would like acknowledge all the children who participated in the study. We also acknowledge the contribution of Dr. Narendra Babu, Associate Professor of Pediatric surgery for helping in performing VCUG and Dr. Murali R Nadig, and Dr. Aisha Naiz, who helped in doing DMSA scan.
Permission from IRB: Yes

Funding: No funding sources.

Conflict of Interest: The authors declare no conflict of interest.

\section{References}

1. Tseng MH, Lin WJ, Tsung WL, Wang SR, Ling Chu M, Wang C. Does a normal DMSA obviate the performance of voiding cystourethrography in evaluation of young children after their first urinary tract infection? J Pediatr 2007 Jan;150(1):96-9.

2. Alper BS, Cirry SH. Urinary tract infection in children. Am Fam Physician 2005 Dec;72(12):2483-8.

3. Indian Society of Pediatric Nephrology. Revised statement on management of urinary tract infections. Indian Pediatr 2011 Sep;48(9):709-17.

4. Zamir G, Sakran W, Horowitz Y, Koren A, Miron D.Urinary tract infection: is there a need for routine renal ultrasonography? Arch Dis Child 2004 May;89(5):466-8. doi: 10.1136/adc.2002.019182.

5. Hellerstein S. Urinary tract infections. Pediatr Clin North Am 1995 Dec;42(6):1433-57.

6. Indian Pediatric Nephrology Group. Consensus statement on management of urinary tract infections. Indian Pediatr 2001 Oct;38(10):1106-15.

7. American Academy of Pediatrics Committee on Quality Improvement, Subcommittee on Urinary Tract Infection. Practice parameter: the diagnosis,treatment, and evaluation of the initial urinary tract infection in febrile infants and young children. Pediatrics 1999 April;103(4):843-52.

8. Ylinen E, Ala-Houhala M, Wikstrom S. Risk of renal scarring in vesicoureteral reflux detected either antenatally or during the neonatal period. Urology 2003 Jun;61(6):1238-42.

9. Alton DJ, LeQuesne GW, Gent R, Siegmann JW, Byard R. Sonographically demonstrated thickening of the renal pelvis in children. Pediatr Radiol 1992;22(6):426-9.

10. Jequier S, Rousseau O. Sonographic measurements of the normal bladder wall in children. Am J Roentgenol 1987 Sep;149(3):563-6. 
11. J. J. Miranda Geelhoed, H. Rob Taal, Eric A. P. Steegers, Lidia R. Arends, Maarten Lequin, Henriëtte A. Moll, Albert Hofman, Albert J. van der Heijden, Vincent W. V. Jaddoe. Kidney growth curves in healthy children from the third trimester of pregnancy until the age of two years. The Generation R Study. Pediatr Nephrol 2010 Feb;25(2):289-298. doi: 10.1007/s00467009-1335-2.

12. Lebowitz RL, Olbing H, Parkkulainen KV, et al. International Reflux Study in Children: international system of radiographic grading of vesicoureteric reflux. Pediatr Radiol 1985 Feb;15(2):105-9.

13. Gabrielle Williams, Jeffery T. Fletcher, Stephen I. Alexander, and Jonathan C. Craig. Vesicoureteral Reflux. J Am Soc Nephrol 2008 May;19(5): 847-862. doi: 10.1681/ASN.2007020245.

14. Weinstein S, Obuchowski NA, Lieber ML. Clinical evaluation of diagnostic tests. Am J Roentgenol 2005 Jan;184(1):14-19.

15. Hansson $S$, Dhamey $M$, Sigstrom $O$, Sixt R, Stokland E, Wennerstrom M, et al. Dimercapto-succinic acid scintigraphy instead of voiding cystourethrography for infants with urinary tract infection. J Urol 2004 Sep;172(3):1071-4.

16. Jakobsson B, Jacobson SH, Hjalmas K. Vesicoureteric reflux and other risk factors for renal damage: identification of high- and low-risk children. Acta Paediatr Suppl 1999 Nov;431(88):31-9.

17. Hoberman A, Charron M, Hickey RW, Baskin M, Kearney DH, Wald ER. Imaging studies after a first febrile urinary tract infection in young children. N Engl J Med 2003 Jan;348(3):195-202.
18. Mahant S, Friedman J, MacArthur C. Renal ultrasound findings and vesicoureteral reflux in children hospitalised with urinary tract infection. Arch Dis Child 2002 Jun;86(6):419-20.

19. Benador D, Benador N, Slosman DO, Nussle D, Mermillod B, Girardin E. Cortical scintigraphy in the evaluation of renal parenchymal changes in children with pyelonephritis. J Pediatr 1994 Jan;124(1):17-20.

20. Fouzas S, Krikelli E, Vassilakos P, Gkentzi D, Papanastasiou DA, Salakos C. DMSA scan for revealing vesicoureteral reflux in young children with urinary tract infection. Pediatrics 2010 Sep;126(3):e513-9. doi: 10.1542/peds.2009-3635.

21. Tsai JD, Huang CT, Lin PY, Chang JH, Lee MD, Huang FY, Shih BF, Hung HY, Hsu CH, Kao HA, Lin CC. Screening high-grade vesicoureteral reflux in young infants with a febrile Urinary Tract Infection. Pediatr Nephrol 2012 Jun;27(6):955-963. doi: 10.1007/s00467-012-2104-1.

22. Preda I, Jodal U, Sixt R, Stokland E, Hansson S. Normal dimercaptosuccinic acid scintigraphy makes voiding cystourethrography unnecessary after urinary tract infection. J Pediatr 2007 Dec;151(6):581-584.

23. Lee MD, Lin CC, Huang FY, Tsai TC, Huang CT, Tsai JD. Screening young children with a first febrile urinary tract infection for high-grade vesicoureteral reflux with renal ultrasound scanning and technetium99m-labeled dimercaptosuccinic acid scanning. J Pediatr 2009 Jun;154(6):797-802. doi: 10.1016/j.jpeds.2008.12.045.

\section{How to cite this article?}

Alkarani T Patil, Sanjeeva G N, Yogesh R, Sowmya K, Ramesh L. Screening of young children between 2-24 months of Age with a first febrile UTI for VUR with imaging modalities. Pediatr Rev: Int J Pediatr Res 2015;2(4):6066.doi:10.17511/ijpr.2015.i04.05 